\title{
Evaluating perceptions of social determinants of health and Part D star performance of Medicare Advantage-contracted primary care providers serving a South Texas market
}

\author{
Ryan Payne, PharmD; Tara Esse, PharmD, BCACP; Jessica Qian, BA; Anjana Mohan, PhD Candidate; \\ Aisha Vadhariya, PhD; Gina Becho-Dominguez, BSN, RN; Omar Serna, PharmD, BCACP; Kim Villarreal, LCSW, CCM; \\ and Susan Abughosh, PhD
}

\section{What is already known about this subject}

- The current literature on the perceptions of primary care providers (PCP) as it relates to social determinants of health (SDoH), especially in medically underserved areas, is scarce.

- Current literature does, however, show that providers tend to believe that the most influential SDoH barriers affecting their populations are financial insecurity, lack of transportation, and lack of education.

\author{
What this study adds \\ - The study examined the perceptions of \\ Medicare Advantage (MA)-contracted \\ PCPs serving a South Texas population, \\ which can reflect $\mathrm{SDoH}$ in that \\ population. \\ - This study examines how the \\ perceptions of MA-contracted PCPs \\ correlate with their CMS Part D star \\ performances, as well as their hospital \\ and emergency room admissions, which \\ have not been previously explored.
}

\author{
Author affiliations \\ Ryan Payne, PharmD; Tara Esse, PharmD, \\ BCACP; Jessica Qian, BA; Gina Becho- \\ Dominguez, BSN, RN; Omar Serna, PharmD, \\ BCACP; and Kim Villarreal, LCSW, CCM, \\ CareAllies, Houston, TX. Anjana Mohan, \\ PhD Candidate, and Susan Abughosh, PhD, \\ University of Houston College of Pharmacy, \\ Houston, TX. Aisha Vadhariya, PhD, \\ Duquesne University, Pittsburgh, PA. \\ AUTHOR CORRESPONDENCE: \\ Ryan Payne, 901.857.1956; \\ ryanpayne.pharmd@gmail.com
}

J Manag Care Spec Pharm 2021;27(5):544-53

Copyright $\odot 2021$, Academy of Managed Care Pharmacy. All rights reserved.

consisting of short answer, ranking, and multiple-choice questions was deployed at attendance-mandatory provider meetings from August to October. Analyses were conducted to understand the providers' $\mathrm{SDoH}$ perceptions. PCP responses were first summarized as frequencies and percentages. Baseline descriptive characteristics of the providers were compared by Medicare star ratings using chi-square tests (for categorical variables) and t-tests (for continuous variables). Group differences in physician beliefs on how SDoH affects patients' overall health (question 1), as well as provider 
beliefs regarding how SDoH affects patients' medication adherence practices (question 2), were assessed using chi-square and t-tests. Associations of provider SDoH perceptions with hospital admissions and emergency room admissions were also assessed. A Fischer's chi-square test was used to examine associations between how PCPs answered the question regarding lack of consistent transportation (question 3) and emergency room admissions. The relationships between PCP perceptions of whose job it is to address SDoH (question 7) and hospital admissions were also evaluated.

RESULTS: The response rate for returned surveys was $89 \%$. Analysis revealed that the top 3 barriers were financial insecurity $(24.87 \%)$, low health literacy (18.65\%), and social isolation (15.03\%). However, about $36 \%$ of PCPs felt they should be the primary addressor of SDoH. There was a significant association between years of practice and CMS Part $D$ star ratings $(P=0.005)$. A significant association between responses in belief towards patients' overall health and CMS Part D star ratings was examined $(P=0.047)$. There was a statistically significant difference in mean hospital admissions with $\mathrm{PCP}$ perception of who should address SDOH $(P=0.03)$. Emergency room admissions was significantly associated with perceptions regarding lack of consistent transportation $(P=0.04)$. No differences with star ratings were observed.

CONCLUSIONS: Previous literature recognize safety and food insecurity as key SDoH barriers. However, they were not among the top $\mathrm{SDoH}$ barriers in our survey. Future research should examine patient perceptions of $\mathrm{SDoH}$ in this population to identify ways providers can better serve their patients.

It has been observed that health follows a social gradient: the higher the socioeconomic position, the better an individual's health. ${ }^{1}$ The importance of social, as opposed to biological or genetic, causes of this gradient has been explored, with housing quality, access to water, access to health care, and quality of work impacting overall health equity. ${ }^{2}$ These nonclinical socioeconomic, environmental, and behavioral factors are collectively known as the social determinants of health (SDoH). Over the past decade, these factors have garnered much interest, as research has indicated their influence on an individual's well-being is extensive. In the literature, it has been suggested that social determinants potentially drive more than $80 \%$ of health outcomes in a population, with medical care only estimated to account for $10 \%-20 \%$ of modifiable contributors. ${ }^{3}$ This increased attention among investigators, health agencies, and health equity advocates alike has led to mounting pressure in practice, research, and policy-making environments to address this growing concern. ${ }^{2}$

Existing literature has mainly focused on defining the effects that $\mathrm{SDoH}$ has on a population in general. For example, neighborhoods may influence health through their physical characteristics, such as air and water quality, and proximity to facilities that produce or store hazardous substances. Additionally, at-home exposure to lead paint, mold, dust, or pest infestation have all been recognized as important factors in respiratory- and nonrespiratoryrelated issues. ${ }^{1,4-6}$ Furthermore, one's occupation has also been recognized as an important factor in defining health-related risk. Jobs requiring repetitive movements and/or high physical workload put workers at higher risk for musculoskeletal injuries and disorders, whereas physically inactive workers in sedentary jobs are at an increased risk of obesity and chronic diseases such as diabetes and heart disease. ${ }^{7,8}$ Physical conditions in the workplace, such as inadequate ventilation, high noise levels, and hazardous chemical exposures, can also cause and exacerbate health issues.

Medicare beneficiaries have the greatest number of SDoH risks, with $33 \%$ having high stress in 3 or more $\mathrm{SDoH}$ domains. ${ }^{9}$ Research has also shown that addressing SDoH barriers in this population can assist with decreasing health care expenditures. For example, Innovative Healthcare Delivery (acquired by naviHealth in 2020) found that focusing on $\mathrm{SDoH}$ resulted in a reduction in hospital readmissions by $33 \%$ for a Medicare Advantage (MA) population, highlighting an association between $\mathrm{SDoH}$ factors and hospital readmission rates. ${ }^{10}$ Yet, regardless of the indication of improved health through addressing social and behavioral factors, a debate remains: who in the health care delivery process should address SDoH?

Arguably, physicians and nonphysician providers are strategically placed to incorporate $\mathrm{SDoH}$ into medical care decision making. However, a 2018 survey of 621 physicians (35\% practiced in primary care) reported that more than $80 \%$ do not believe it is their job to find solutions to $\mathrm{SDoH}$ barriers. ${ }^{11}$ The American Academy of Family Physicians (AAFP) also surveyed family physicians to determine the extent that they are engaged in addressing $\mathrm{SDoH}$ in their respective practices, as well as to identify perceived barriers. $^{12}$ Of a random sampling of 5,000 physicians, AAFP received 434 (8.7\%) responses where $81.1 \%$ stated that they "engaged in at least one clinical action," while $43.3 \%$ stated that they were "engaged in at least one populationbased action." Clinical actions included screening patients, referring patients to community-based organizations, capturing $\mathrm{SDoH}$ data in their medical records, and hiring community health workers, while population-based actions included communicating with elected officials about policies supporting $\mathrm{SDoH}$, providing testimony of support for policies, and involvement in community health initiatives to address SDoH. 
In addition, the respondents reported that time (80.0\%) and staffing (64.5\%) were the most common barriers to addressing $\mathrm{SDoH} .^{12}$ It was noted that physician experience was associated with higher levels of clinical engagement; lower median household income areas where physicians practiced were associated with higher levels of populationbased engagement; and working for a federally qualified health center was associated with both.

This study provides initial data about physician and nonphysician provider engagement in addressing $\mathrm{SDoH}$, and the findings suggest that some physicians, but not all, are using clinical interventions and/or population-based strategies to address $\mathrm{SDoH}$. The level of commitment in addressing $\mathrm{SDoH}$ is varied, and several barriers were identified. It was noted that providers practicing in disadvantaged communities engaged in more population-based activities but not clinical activities, which raises questions about the value providers place on clinical interventions to address $\mathrm{SDoH}$.

Additional opportunities have arisen to assess provider views of SDoH. The Physician's Foundation's 2018 Survey of America's Physicians asked family physicians to specify how many of their patients were affected by a social situation that posed a serious impediment to their health, such as poverty, unemployment, lack of education, or drug addiction..$^{13}$ Most physician respondents (87.9\%) indicated that social conditions impacted some, many, or all of their patients negatively, influencing health. Thus, providers acknowledged that nonmedical factors may have a greater negative impact on the overall health of their patients..$^{13}$ For many physicians, this was extremely eye opening when considering the extent to which poverty, lack of education, and other social conditions were impacting their patients' health.

In a Waystar survey completed by American consumers, $68 \%$ mentioned they had at least some level of SDoH barriers, but only $22 \%$ had discussed these issues with their physicians. ${ }^{14}$ Unaddressed $\mathrm{SDoH}$ barriers severely limit the ability of providers to positively influence their patients' health, and a key factor of physician burnout is the inability to address the root causes of their patients' poor health adherence. ${ }^{15,16}$ Moreover, these unaddressed SDoH factors often converge during hospital admissions, where the impact of social conditions may contribute to poorer outcomes. ${ }^{15}$ Individuals who received community-based services, particularly those that emphasize screening for $\mathrm{SDoH}$, experienced a $26.3 \%$ drop in inpatient hospital admission rates. ${ }^{17}$
Although several studies have reviewed provider perceptions of SDoH, no studies have been observed to correlate provider responses to patient inpatient use or medication adherence, specifically within the MA space. Therefore, the primary objective of this study was to understand MA-contracted primary care providers ( $\mathrm{PCP}$ ) perceptions of $\mathrm{SDoH}$ and to investigate the correlation between their perceptions and their Centers for Medicare \& Medicaid Services (CMS) Part D star performances. The secondary objective of this study was to examine the association between provider perceptions of $\mathrm{SDoH}$ with emergency room visits and hospital admissions per 1,000.

\section{Methods}

Survey data collected from MA-contracted PCPs serving beneficiaries within a South Texas market was examined in this study. These physicians treat commercial patients in addition to the MA plan patients. The survey was distributed during the 2019 calendar year and contained 8 assessment areas consisting of short answer, ranking, and multiple-choice questions (Figure 1). The survey measured provider perceptions surrounding $\mathrm{SDoH}$ but had a specific aim of answering these following 3 overarching questions:

1. Do providers believe that $\mathrm{SDoH}$ plays a role in their patients' overall health and medication adherence practices?

2. What do providers feel are the most important $\mathrm{SDoH}$ barriers facing their patient population?

3. Whose responsibility do they believe it is to address $\mathrm{SDoH}$ ?

The survey instrument was developed after a review of existing literature. ${ }^{12,18,19}$ Face and content validity was assessed through a focus group of MA-plan medical directors to determine if the survey was adequate to obtain the necessary data. Physical copies of the survey were distributed at attendance-mandatory provider meetings from August to October 2019. For providers not in attendance, copies were sent via email. The instrument took less than 5 minutes to complete, and PCPs were instructed to submit completed surveys at the end of these meetings for those in attendance or via technological means for those who were absent (eg, email or facsimile).

All MA-contracted PCPs were given the opportunity to participate in this study without regard to outside factors, such as length of time contracted with the health plan or CMS performance scores. PCPs were only excluded from this study if they refused to complete and return the survey. Provider demographic information such as age, race, and sex were collected from the Texas Medical Board's 


\section{FIGURE 1 PCP SDOH Survey}

1. I believe that social factors play a role in $\%$ of my patients' OVERALL HEALTH.
$\square 0 \%-10 \%$
$\square 11 \%-25 \%$
$\square 26 \%-50 \%$
$51 \%-75 \%$
$\square 76 \%-100 \%$

2. I believe that social factors play a role in $\%$ of my patients' MEDICATION ADHERENCE PRACTICES.
0\%-10\%
$\square 11 \%-25 \%$
$\square 26 \%-50 \%$
$51 \%-75 \% \square 76 \%-100 \%$

3. What \% of your patients today do you feel are affected by each of the following social factors? Please note: your numbers do not need to add up to $100 \%$. Please mark an " $X$ " in the appropriate box.

\begin{tabular}{|c|c|c|c|c|c|}
\hline Social factor & $0 \%-10 \%$ & $11 \%-25 \%$ & $26 \%-50 \%$ & $51 \%-75 \%$ & $76 \%-100 \%$ \\
\hline \multicolumn{6}{|l|}{ a. Social isolation } \\
\hline \multicolumn{6}{|l|}{ b. High stress } \\
\hline \multicolumn{6}{|l|}{ c. Depression } \\
\hline \multicolumn{6}{|l|}{ d. Low health literacy } \\
\hline \multicolumn{6}{|l|}{ e. Food insecurity } \\
\hline \multicolumn{6}{|c|}{ f. Low income/financial insecurity } \\
\hline \multicolumn{6}{|c|}{ g. Lack of affordable housing } \\
\hline \multicolumn{6}{|c|}{ h. Access to amenities (eg, air conditioning, water, electricity) } \\
\hline \multicolumn{6}{|c|}{ i. Lack of consistent transportation } \\
\hline \multicolumn{6}{|c|}{ j. Unsafe neighborhoods/safety } \\
\hline k. Caregiver burden & & & & & \\
\hline
\end{tabular}

4. What do you believe are the top THREE (3) most important social determinants of health in your patient population?

1.

2.

3.

5. What do you think is the biggest barrier to addressing social determinants of health in your practice?

$\square$ No opinion $\square$ Lack of patient engagement $\square$ Lack of community resources $\square$ Lack of family support

$\square$ Lack of knowledge of opportunities to address social determinants of health

$\square$ Other (please specifiy):

6. Do you think addressing social determinants of health is the responsibility of the primary care health care provider?

$\square$ No opinion $\square$ No $\square$ Maybe $\square$ Yes

7. Please rank, in order of most influential (1) to least influential (6), whose job SHOULD IT BE to address social determinants of health, outside of the patients themselves?

$\mathrm{PCP} \_$Insurers___ Employers___ Local religious organizations/nonprofit charities

State government___ Federal government

8. Please indicate your recommendations regarding how to best address social determinants of health.

Thank you for taking time out to participate in our survey. We truly value the information you have provided.

$P C P=$ primary care provider $\mathrm{SDoH}=$ social determinants of health 


\section{TABLE 1 Evaluation of Association Between Provider Demographics and Medicare Star Ratings}

\begin{tabular}{|c|c|c|c|}
\hline Variables & $\begin{array}{c}\text { Medicare star rating } \\
<5(n=23)\end{array}$ & $\begin{array}{c}\text { Medicare star rating } \\
>5(n=45)\end{array}$ & $P$ value \\
\hline \multicolumn{4}{|l|}{ Age } \\
\hline Mean age in years (SD) & $56(13.80)$ & $(9.87)$ & 0.510 \\
\hline \multicolumn{4}{|l|}{ Age group, n (\%) } \\
\hline below 49 years & $8(34.78)$ & $12(26.67)$ & \\
\hline $50-60$ years & $6(26.09)$ & $18(40.00)$ & 0.530 \\
\hline above 60 years & $9 \quad(39.13)$ & $15(33.33)$ & \\
\hline \multicolumn{4}{|l|}{ Years of practice, $n(\%)$} \\
\hline Mean years of practice (SD) & $22.16(13.76)$ & $21.84(18.50)$ & 0.750 \\
\hline below 10 years & $7(30.43)$ & $3 \quad(6.67)$ & \\
\hline $10-20$ years & $2 \quad(8.70)$ & $17(37.78)$ & $0.005^{a}$ \\
\hline above 20 years & $14(60.87)$ & $25(55.55)$ & \\
\hline \multicolumn{4}{|l|}{ Sex, n (\%) } \\
\hline Female & $7(30.43)$ & $16(35.56)$ & 0.780 \\
\hline Male & $16(69.57)$ & $29(64.44)$ & \\
\hline \multicolumn{4}{|l|}{ Ethnicity, n (\%) } \\
\hline No answer/unknown & 9 (39.13) & $2 \quad(4.44)$ & \\
\hline Asian/Black/Caucasian & $6(26.09)$ & $13(28.89)$ & $0.001^{\mathrm{a}}$ \\
\hline Hispanic/Latino/Native American & $8(34.78)$ & $30(66.67)$ & \\
\hline \multicolumn{4}{|l|}{ Area of practice, $n(\%)$} \\
\hline Internal medicine & $8(34.78)$ & $19(42.22)$ & \\
\hline Family medicine & $14(60.87)$ & $23(51.11)$ & 0.830 \\
\hline Other & $1 \quad(4.35)$ & $(6.67)$ & \\
\hline \multicolumn{4}{|c|}{ SDoH plays a role in medication adherence (question 2 response) } \\
\hline$<50 \%$ of patients & $5(21.74)$ & $14(31.82)$ & 0.384 \\
\hline$\geq 50 \%$ of patients & $18(78.26)$ & $30(68.18)$ & \\
\hline
\end{tabular}

website. CMS Part D star ratings, hospital admission, and emergency room admission rates for providers were also collected and analyzed, although these data were obtained from internal reporting systems. Survey data were subsequently deidentified for analysis and stored using Microsoft Excel 2013 (Microsoft Corporation).

The following analyses were conducted to understand provider $\mathrm{SDoH}$ perceptions, using the World Health Organization's framework. First,
PCP responses were summarized as frequency and percentages. Second, baseline descriptive characteristics responded to survey question 2 (percentage of patients for whom $\mathrm{SDOH}$ played a role in medication adherence), were compared with CMS star ratings ( 5 vs below 5 ) using chi-square tests (for categorical variables) and t-tests (for continuous variables). A multivariate logistic regression with the outcome of CMS star ratings was also of the PCPs, as well as how they carried out. Third, group differences in PCP beliefs regarding how $\mathrm{SDoH}$ affects the overall health of patients (question 1), as well as PCP beliefs regarding how $\mathrm{SDoH}$ affects patient medication adherence practices (question 2), with various provider characteristics, were assessed using chi-square and t-tests. Associations of PCP SDoH perceptions with hospital admission and emergency room admission rates were also evaluated. In addition, a Fischer's chi-square test was used to examine connections between how PCPs answered the question regarding lack of consistent transportation (question 3i) and emergency room admissions.

Finally, an unadjusted general linear model was used to test the relationships between PCP perceptions of whose job it is to address SDoH (question 7) and hospital admission rates. Options included PCPs, insurers, employers, local religious organizations, or nonprofit charities, state government, and federal government. The primary outcome was hospital admissions. All statistical analyses were performed using SAS software version 9.4 (SAS Institute) at an a priori significance level of 0.05 . The study was approved by the institutional review board at the University of Houston.

\section{Results}

The response rate for the survey distributed to MA-contracted PCPs was $89 \%(\mathrm{n}=77)$. Among the respondents, 70 (91\%) were physicians; 4 (5\%) were nurse practitioners; and 3 (4\%) were physician assistants. Baseline characteristic are shown in Table 1. Most of the study participants were male (63.63\%), and half (53\%) were Hispanic/Latino. The mean age of providers was 53.5 years, and on average, number of years in practice was 22 . 


\begin{tabular}{c|c|cc}
\multicolumn{2}{c}{ TABLE 2 } & SDoH Barrier Rankings & \multicolumn{2}{c}{$\mathbf{n}(\%)$} \\
\hline Ranking & Variable & $48(24.87)$ \\
\hline 1 & Financial insecurity & $36(18.65)$ \\
\hline 2 & Low health literacy & $29(15.03)$ \\
\hline 3 & Social isolation & $24(12.44)$ \\
\hline 4 & Lack of consistent transportation & $16(8.29)$ \\
\hline 5 & Depression & $12(6.22)$ \\
\hline 6 & Others & 9 & $(4.66)$ \\
\hline 7 & Caregiver burden & 8 & $(4.15)$ \\
\hline 8 & Access to amenities & 7 & $(3.63)$ \\
\hline 9 & High stress & 3 & $(1.55)$ \\
\hline 10 & Food insecurity & 1 & $(0.52)$ \\
\hline 11 & Safety & \\
\hline
\end{tabular}

$\mathrm{SDoH}=$ social determinants of health.

Analysis of survey responses revealed that the top 3 SDoH barriers were financial insecurity (24.87\%), low health literacy (18.65\%), and social isolation (15.03\%). Safety (0.52\%) and food insecurity $(1.55 \%)$ were ranked among the least important SDoH barriers (Table 2). When rank ordering whose role it should be to address $\mathrm{SDoH}, 36 \%$ felt that PCPs should be the primary addressor of SDoH, followed by insurers (28.57\%) and state/federal governments (27.28\%). Only $2.60 \%$ of PCPs felt that employers should be the primary addressors of SDoH (Table 3).

There was a significant association between years of practice and CMS Part D star ratings $(P=0.005)$, meaning that there is a trend with the years of practice. Racial differences in PCP views may exist, but this was unable to be fully ascertained because of the limited sample size of the different racial groups within the study. No significant difference was observed between PCP perceptions of the SDoH impact on patient medication adherence with their CMS Part D star ratings (Table 1). In addition, no significant predictors of CMS Part D star ratings were identified in the logistic model (data not shown).

Interestingly, those who ranked PCPs as the primary addressor of $\mathrm{SDoH}$ had a higher mean hospital admission rate (192.78 vs 167.03). There was a statistically significant association between emergency room admissions and SDoH perceptions regarding the lack of consistent transportation $(P=0.04)$. Mean emergency room admission rates were higher among PCPs who perceived that less than one fourth of their population was affected by lack of consistent transportation (427.8 vs 402.3; Table 4). When asked whose job it is to address $\mathrm{SDoH}$ (question 7), there was a statistically

\section{TABLE 3 Question 7: Whose job should it be to address SDoH?}

\begin{tabular}{c|c|c}
\hline Ranking & Variable & Yes (\%) \\
\hline 1 & PCPs & $28(36.36)$ \\
\hline 2 & Insurers & $22(28.57)$ \\
\hline 3 & State & $11(14.29)$ \\
\hline 4 & Federal & $10(12.99)$ \\
\hline 5 & Charity & $4 \quad(5.19)$ \\
\hline 6 & Employers & $2 \quad(2.60)$ \\
\hline
\end{tabular}

$P C P=$ primary care provider; $S D \circ H=$ social determinants of health.

significant association between mean hospital admission rate and PCPs who responded that it should be the job of PCPs to address SDoH $(P=0.03)$. Other variables were not significant and therefore were not reported.

\section{Discussion}

The top $4 \mathrm{SDoH}$ barriers identified in this study were financial insecurity, low health literacy, social isolation, and lack of consistent transportation (Figure 1). In a similar study conducted by Anthem and Quid on the perceptions of $\mathrm{SDoH}$, the top SDoH barriers that they identified were education, income, and transportation. In their study, however, social isolation was not identified as a significant SDoH barrier. ${ }^{3}$ Conversely, in this study's population, social isolation was deemed significant by PCPs residing in South Texas.

Of note, the primary patient population receiving care from the MA-contracted providers were of Hispanic ethnicity, which may reflect racial differences in the importance of this barrier. Research identified regarding SDoH barriers specific to the Hispanic community show that Hispanics face health care access barriers and, as a result, use fewer health screenings and have less follow-up care. ${ }^{20}$

Hispanic patients, on average, face more economic and cultural barriers in health care than their non-Hispanic White counterparts. ${ }^{20,21}$ Moreover, because of the previously mentioned economic and cultural barriers, Hispanics report delaying or forgoing medical care, including obtaining needed prescriptions, as compared with non-Hispanic White patients. ${ }^{20,21}$ Chronic illness increases this financial burden, especially among the minority population, ${ }^{14,18}$ while there is a significant positive correlation between financial insecurity and mortality rates..$^{22,23}$

Health literacy impacts the ability of patients to comprehend some recommendations of health care providers 


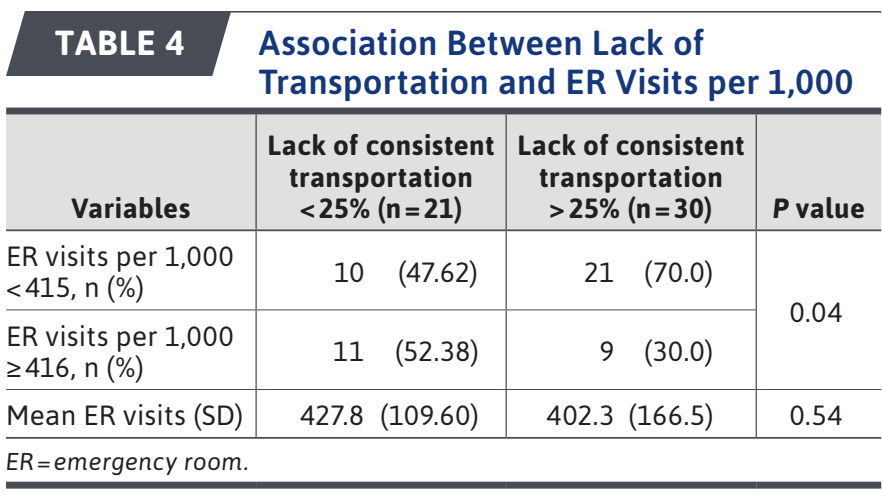

and make appropriate decisions to manage their health. Low health literacy has been shown to be associated with depression and increased rates of diabetes-related mortality. ${ }^{24,25}$ Social cohesion decreases stress levels, thereby improving the well-being of patients. ${ }^{21}$ This is in line with the provider beliefs that social isolation is one of the domains of $\mathrm{SDoH}$ that is faced by their patient populations. Travel distance and inconsistent transportation, especially in rural areas, limit patient access to care ${ }^{26}$ which is consistent with the perceptions of the MA-contracted PCPs. Hence, from a provider's perspective, it is essential that $\mathrm{SDoH}$ be assessed and addressed.

Food insecurity is also strongly associated with obesity, poor glycemic control, depression, and negative health outcomes. ${ }^{27}$ However, in this study, providers felt that their patient populations were least affected by food insecurity. Furthermore, in our study, safety and food insecurity were not among the top SDoH barriers identified, although previous literature has recognized them as key SDoH factors. In a 2011 study by Billimek and Sorkin, it was found that neighborhood safety had a significant impact on medication adherence. This study indicated that self-reported neighborhood safety was associated with treatment nonadherence. In fact, patients living in unsafe neighborhoods reported delays in filling a prescription. This study concluded that neighborhood safety may contribute to treatment nonadherence in daily life, even when the quality of care delivered in the clinic is not diminished. ${ }^{28}$

Only one-third of the MA-contracted PCPs believe they should play a substantial role in addressing SDoH. This highlights the fact that two-thirds of PCPs did not feel that they should play a substantial role in addressing SDoH barriers among their patients. Such beliefs can have an effect on patient care, since they may preclude a conversation with the patients that can help identify some of these barriers and perhaps refer patients to resources they may be unaware of. These providers may benefit from additional education on the clinical impact of $\mathrm{SDoH}$, as well as community resources available for addressing these clinically significant social issues.

More work is needed to encourage and motivate PCPs to address $\mathrm{SDoH}$, as well as to pinpoint the role they and their offices can play in connecting patients to appropriate community resources to address these barriers. It has been shown that only $15.6 \%$ of PCPs screen patients for all of the 5 domains of SDoH recommended by CMS. ${ }^{26}$ Poor screening practices will ultimately allow $\mathrm{SDoH}$ barriers to go unaddressed, thus, having a negative effect on patient overall health outcomes.

Survey respondents who ranked PCPs as the primary addressor of SDoH had, on average, a higher hospital admission rate. Originally, it was hypothesized that if survey respondents ranked PCPs as the primary addressor, it would be those PCPs currently addressing SDoH and thus would have lower hospital admissions due to the inclusion of $\mathrm{SDoH}$ into clinical practice. The results of this study showed the contrary; one potential reason for this finding could be that respondents ranking PCPs as the primary addressor may have patient populations with a higher $\mathrm{SDoH}$ burden. Another potential reason could be that providers recognize these $\mathrm{SDoH}$ factors and the role that they play, but they may not have the tools to address them, since they may not know what resources are available to assist their patients in addressing these barriers.

There was a significant association between emergency room admissions and lack of consistent transportation. Transportation is an important barrier that has been shown to impact patient care. In a pilot study, emergency room visits were cut by $46 \%$ when $\mathrm{SDoH}$ issues were addressed ${ }^{29}$; this included arranging transportation. PCPs should examine the impact of inconsistent transportation and consult the appropriate professional to address this barrier. In our survey-based study, we were unable to ascertain whether PCPs tried to address transportation issues, but this should be evaluated in future research.

It is also noteworthy to point out that providers surveyed were not exclusively contracted with MA plans. Many of these practitioners also serve commercial and accountable care organization patients. Because the survey was generic in nature, the question involving the most influential in the health care value chain for addressing SDoH (question 7) was comprehensive and included an "employer" selection. This, however, should not distract from the efforts of the study to identify the perceptions of providers regarding their ranking of influence in addressing $\mathrm{SDoH}$. 
Understanding PCP perceptions and attitudes towards $\mathrm{SDoH}$ offers added insight into ways they can better manage chronic health conditions and presents opportunities for stakeholders to improve service for patients. Without a more complete understanding of how patients perceive the role of $\mathrm{SDoH}$, however, stakeholders, including PCPs and health care payers, risk missing opportunities to address SDoH-induced gaps in care and interact with their patients more effectively. ${ }^{30}$ Stakeholders can mobilize the community-level resources to address $\mathrm{SDoH}$ and reduce the increased costs related to poor outcomes. Health care providers should identify patients with poor socioeconomic status and aid them in comprehending the health risks associated with social factors. Furthermore, clinicians should take the initiative to better understand their patients' lives and provide patient-centered care, which will improve the patient health outcome. All the stakeholders must integrate $\mathrm{SDoH}$ into the conventional approach of patient care to improve the health of their patient populations.

\section{LIMITATIONS}

There were several limitations in the study. First, the sample size in this study was small, which may have impacted the power to detect existing significant differences. Additionally, the PCPs in this study were limited to the South Texas geographical region, and all were part of independent physician associations; thus, generalizability may be limited to similar populations.

Second, given that this study relied on survey responses, and the surveys were disseminated at mandatory provider meetings (for the most part), there is a potential for the Hawthorne Effect, which may have resulted in participant response bias. The survey outcomes may have been different if the study had been conducted in a different environment. ${ }^{31,32}$

Third, PCPs were not surveyed as to their knowledge regarding community-based resources that were available to assist patients affected by social factors, nor were they surveyed regarding their comfort level in discussing $\mathrm{SDoH}$ with their patients. This information would be important to include in future studies.

Fourth, there may have been other $\mathrm{SDoH}$ barriers that were missed in this survey. The content of the survey was intended to be completed within 3 to 5 minutes and consisted of 1 page to enhance completion. Because there are numerous $\mathrm{SDoH}$ barriers, the omission of an SDoH factor in this study cannot be discounted.

Fifth, hospital admissions/emergency room admission rates, as well as CMS Part D star ratings, were unreported for a few respondents; hence those PCPs were excluded from the analysis.

Finally, some findings were based on unadjusted analysis. Future studies with multivariate analysis that control for potential confounding in larger samples are warranted.

\section{Conclusions}

It cannot be overstated that $\mathrm{SDoH}$ can have a significant effect on individual health outcomes. In a world of increasing health care costs and a drive towards value-based care, it is now more important than ever to focus on whole-person health. The incorporation of $\mathrm{SDoH}$ into clinical care could help drive down health care costs and use. . $^{33,34}$

PCPs are in an optimal position to assess $\mathrm{SDoH}$ in their practices because of regular, close engagement with patients. Therefore, assessing the perceptions of PCPs is one of the first steps in addressing patient-faced social barriers. By understanding PCP perceptions, health care organizations can create and tailor education materials, tools, and resources for provider empowerment.

Future research should examine patient perceptions of $\mathrm{SDoH}$ in this population to identify any potential gaps between patient experiences and PCP perceptions. This will help to further pinpoint ways that PCPs, and payers, can better serve and interact with their patients.

\section{DISCLOSURES}

Funding for this study was provided by CareAllies, a Cigna business. Statistical analysis was completed in partnership with the University of Houston. Payne, Esse, Qian, Serna, Villarreal, and BechoDominguez are employees of CareAllies. Mohan and Abughosh are employed by the University of Houston College of Pharmacy. Abughosh reports grants from Valeant and Regeneron/Sanofi, unrelated to this work. Vadhariya has nothing to disclose.

This research was presented virtually at the AMCP Pharmacist Virtual Learning Days event, April 2020, as well as the American College of Clinical Pharmacy Virtual Poster Symposium, May 26-27, 2020.

\section{ACKNOWLEDGMENTS}

The authors thank the nurses, social workers, and office staff who helped in the dissemination and collection of PCP surveys. The authors also thank Katherine Walters for her role in this project.

\section{REFERENCES}

1. Commission on Social Determinants of Health. Closing the Gap in a Generation: Health Equity Through Action on the Social Determinants of Health. Final Report. World Health Organization; 2008. Accessed July 13, 2020. https://www.who. int/social_determinants/final_report/ csdh finalreport 2008.pdf 
2. Braveman P, Egerter S, Williams DR. The social determinants of health: coming of age. Annu Rev Public Health. 2011;32:381-98. doi: 10.1146/ annurev-publhealth-031210-101218

3. Anthem Public Policy Institute, Quid. Bridging gaps to build healthy communities: opportunities to better address social determinants to improve health. Anthem Public Policy Institute. May 2019. Accessed July 13, 2020. https://www.anthempublicpolicyinstitute.com/userFiles/ uploads $/ 28 / 28$ Report Bridging-Gapsto-Build-Healthy-Communities.pdf

4. Chuang Y-C, Cubbin C, Ahn D, Winkleby MA. Effects of neighbourhood socioeconomic status and convenience store concentration on individual level smoking. J Epidemiol Community Health. 2005;59(7):568-573. doi: 10.1136/ jech.2004.029041

5. Giles-Corti B, Donovan RJ. Relative influences of individual, social environmental, and physical environmental correlates of walking. Am J Public Health. 2003;93(9):1583-89. doi: 10.2105/

ajph.93.9.1583

6. O'Neil BA, Forsythe ME, Stanish WD. Chronic occupational repetitive strain injury. Can Fam Physician. 2001;47:311316. Accessed March 31, 2021. https:// www.ncbi.nlm.nih.gov/pmc/articles/ PMC2016244/

7. Warburton DER, Nicol CW, Bredin SSD. Health benefits of physical activity: the evidence. CMAJ. 2006;174(6):801-09. doi: 10.1503/cmaj.051351

8. Institute for Clinical Systems Improvement, Robert Wood Johnson Foundation. Going beyond clinical walls: solving complex problems. Network for Regional Healthcare Improvement. October 2014. Accessed July 17, 2020. http://www.nrhi.org/uploads/ going-beyond-clinical-walls-solving-complex-problems.pdf
9. Abraham T. 1 in 5 patients at high risk of socioeconomic health problem, survey finds. Healthcare Dive. December 12, 2018. Accessed July 17, 2020. https://www. healthcaredive.com/news/1-in-5-patients-at-high-risk-of-socioeconomichealth-problem-survey-finds/544233/

10. Innovative Healthcare Delivery. Study shows non-clinical program reduces hospital readmissions by 33\% [press release]. July 23, 2019. Accessed April 7, 2021. https://navihealth.com/wp-content/ uploads/naviHealth-Readmission-Reduction-White-Paper.pdf

11. Rosenberg J. Social determinants of health are important, but who is responsible for addressing them? Am J Manag Care. June 18, 2018. Accessed July 17, 2020. https://www.ajmc.com/view/ social-determinants-of-health-areimportant-but-who-is-responsible-foraddressing-them

12. Kovach KA, Reid K, Grandmont J, Jones D, Wood J, Schoof B. How engaged are family physicians in addressing the social determinants of health? A survey supporting the American Academy of Family Physicians health equity environmental scan. Health Equity. 2019;3(1):449-57. doi: 10.1089/ heq.2019.0022

13. Leavitt Partners. More than $80 \%$ of doctors say it isn't their job to fix social determinants of health. (But that's not quite as alarming as it seems.) Advisory Board Daily Briefing. May 15, 2018.

Accessed July 13, 2020. https://www. advisory.com/daily-briefing/2018/05/15/ social-determinants

14. Waystar. Clinical Consumer Survey Consumer perspectives on how social determinants impact clinical experience. Waystar. December 14, 2018. Accessed July 13, 2020. https://www.waystar.com/ blog-clinical-consumer-survey-consumer-perspectives-on-how-social-determinants-impact-clinical-experience/

15. Axelson DJ, Stull MJ, Coates WC. Social determinants of health: a missing link in emergency medicine training. AEM Educ Train. 2017;2(1):66-68. doi: 10.1002/ aet2.10056
16. Valenti J. We must address social determinants of health now. Medical Economics. November 14, 2019. Accessed July 13, 2020. https://www. medicaleconomics.com/view/we-mustaddress-social-determinants-health-now

17. Kent J. Social determinants screenings cut hospital admissions by nearly $30 \%$. HealthITAnalytics. July 23, 2019. Accessed July 13, 2020. https://healthitanalytics.com/news/ social-determinants-screenings-cut-hospital-admissions-by-nearly-30

18. Wallace AS, Luther B, Guo J-W, Wang C-Y, Sisler S, Wong B. Implementing a social determinants screening and referral infrastructure during routine emergency department visits, Utah, 2017-2018. Prev Chronic Dis. 2020;17:E45. doi:10.5888/pcd17.190339

19. National Association of Community Health Centers. About the PRAPARE Assessment Tool. Accessed September 2, 2019. https://www.nachc.org/researchand-data/prapare/about-the-prapareassessment-tool/

20. Shoemaker ML, White MC. Breast and cervical cancer screening among Hispanic subgroups in the USA: estimates from the National Health Interview Survey 2008, 2010, and 2013. Cancer Causes Control. 2016;27(3):453-57. doi:10.1007/ s10552-016-0718-5

21. Dominguez K, Penman-Aguilar A, Chang $\mathrm{M}-\mathrm{H}$, et al. Vital signs: leading causes of death, prevalence of diseases and risk factors, and use of health services among Hispanics in the United States - 2009-2013. MMWR Morb Mortal Wkly Rep. 2015;64(17):469-78. Accessed March 26, 2021. https://www.ncbi.nlm. nih.gov/pmc/articles/PMC4584552/

22. Jack L, Jack NH, Hayes SC. Social determinants of health in minority populations: a call for multidisciplinary approaches to eliminate diabetes-related health disparities. Diabetes Spectrum. 2012;25(1):9-13. doi:10.2337/diaspect.25.1.9

23. Singh GK, Siahpush M. Widening socioeconomic inequalities in U.S. life expectancy, 1980-2000. Int J Epidemiol. 2006;35(4):969-79. doi:10.1093/ije/dyl083 
24. Healthy People 2020. Health literacy. Accessed July 13, 2020. https://www. healthypeople.gov/2020/topics-objectives/topic/social-determinants-health/ interventions-resources/health-literacy

25. Healthy People 2020. Social cohesion. Accessed July 15, 2020. https://www. healthypeople.gov/2020/topics-objectives/topic/social-determinants-health/ interventions-resources/social-cohesion

26. Fraze TK, Brewster AL, Lewis VA, Beidler LB, Murray GF, Colla CH. Prevalence of screening for food insecurity, housing instability, utility needs, transportation needs, and interpersonal violence by U.S. physician practices and hospitals. JAMA Netw Open. 2019;2(9):e1911514. doi:10.1001/ jamanetworkopen.2019.11514

27. Silverman J, Krieger J, Kiefer M, Hebert P, Robinson J, Nelson K. The Relationship between food insecurity and depression, diabetes distress and medication adherence among low-income patients with poorly-controlled diabetes. J Gen Int Med. 2015;30(10):1476-80. doi:10.1007/s11606-015-3351-1
28. Billimek J, Sorkin DH. Self-reported neighborhood safety and nonadherence to treatment regimens among patients with type 2 diabetes. J Gen Int Med. 2011;27(3):292-96. doi:10.1007/ s11606-011-1882-7

29. Epic Outcomes. 46\% fewer ED visits by addressing social determinants of health. Epic. June 8, 2020. Accessed July 16, 2020. https://www.epic.com/epic/ post/46-fewer-ed-visits-addressingsocial-determinants-health

30. Heath S. Using social determinants of health in patient-centered care. PatientEngagementHIT. June 15, 2017. Accessed June 4, 2020. https:// patientengagementhit.com/news/ using-social-determinants-of-health-inpatient-centered-care

31. Paradis E, Sutkin G. Beyond a good story: from Hawthorne Effect to reactivity in health professions education research. Med Educ. 2017;51(1):31-39. doi:10.1111/ medu.13122
32. Kurtz SL. Measuring and accounting for the Hawthorne effect during a direct overt observational study of intensive care unit nurses. Am J Infect Control. 2017;45(9):995-1000. doi:10.1016/j. ajic.2017.03.022

33. Magnan S. Social determinants of health 101 for healthcare: five plus five. Discussion paper. NAM Perspectives. October 9, 2017. Accessed March 26, 2021. https://doi.org/10.31478/201710c

34. Ferrer RL, Schlenker CG, Romero RL, et al. Advanced primary care in San Antonio: linking practice and community strategies to improve health. J Am Board Fam Med. 2013;26(3):288-98. doi:10.3122/ jabfm.2013.03.120238 